\title{
Receptive vocabulary differences in monolingual and bilingual adults
}

\section{Citation}

BIALYSTOK, ELLEN, and GIGI LUK. 2012. "Receptive vocabulary differences in monolingual and bilingual adults." Bilingualism: Language and Cognition 15 (02) (April 11): 397-401. doi:10.1017/ S136672891100040X. http://dx.doi.org/10.1017/S136672891100040X.

\section{Published Version}

doi:10.1017/S136672891100040X

\section{Permanent link}

http://nrs.harvard.edu/urn-3:HUL.InstRepos:11384944

\section{Terms of Use}

This article was downloaded from Harvard University's DASH repository, and is made available under the terms and conditions applicable to Open Access Policy Articles, as set forth at http:// nrs.harvard.edu/urn-3:HUL.InstRepos:dash.current.terms-of-use\#OAP

\section{Share Your Story}

The Harvard community has made this article openly available.

Please share how this access benefits you. Submit a story.

Accessibility 


\section{Bilingualism: Language and Cognition}

http://journals.cambridge.org/BIL

Additional services for Bilingualism: Language and Cognition:

Email alerts: $\underline{\text { Click here }}$

Subscriptions: $\underline{\text { Click here }}$

Commercial reprints: $\underline{\text { Click here }}$

Terms of use : $\underline{\text { Click here }}$

\section{Receptive vocabulary differences in monolingual and bilingual adults}

\section{ELLEN BIALYSTOK and GIGI LUK}

Bilingualism: Language and Cognition / Volume 15 / Issue 02 / April 2012, pp 397 - 401

DOI: 10.1017/S136672891100040X, Published online: 11 November 2011

Link to this article: http://journals.cambridge.org/abstract_S136672891100040X

How to cite this article:

ELLEN BIALYSTOK and GIGI LUK (2012). Receptive vocabulary differences in monolingual and bilingual adults. Bilingualism: Language and Cognition, 15, pp 397-401 doi:10.1017/S136672891100040X

Request Permissions : $\underline{\text { Click here }}$ 
RESEARCH NOTES

\section{Receptive vocabulary differences in monolingual and bilingual adults*}

(Received: April 9, 2011; final revision received: July 6, 2011; accepted: July 18, 2011; first published online November 11, 2011)
ELLEN BIALYSTOK

York University

GIG I LUK

Harvard Graduate School of Education

\begin{abstract}
English receptive vocabulary scores from 797 monolingual and 808 bilingual participants between the ages of 17 and 89 years old were aggregated from 20 studies to compare standard scores across language groups. The distribution of scores was unimodal for both groups but the mean score was significantly different, with monolinguals obtaining higher standard scores than bilinguals. Consistent with previous research, older adults had higher vocabulary scores than younger adults. The results are discussed in terms of the implications for theoretical conceptions of linguistic processing and clinical diagnosis in bilingual populations.
\end{abstract}

Keywords: receptive vocabulary, adult bilinguals, linguistic performance

A large body of research has documented differences in linguistic ability between monolingual and bilingual adults on tests that require lexical access and fluency. For example, bilinguals produce fewer words than monolinguals on verbal fluency tests (Gollan, Montoya \& Werner, 2002; Rosselli, Ardila, Araujo, Weekes, Caracciolo, Padilla \& Ostrosky-Solis, 2000), require longer response times than monolinguals on picture naming tasks (Gollan, Fennema-Notestine, Montoya \& Jernigan, 2007; Gollan, Montoya, Fennema-Notestine \& Morris, 2005; Roberts, Garcia, Desrochers \& Hernandez, 2002), make more errors on a speeded version of the task (Bialystok, Craik \& Luk, 2008a), experience more tip-of-the-tongue episodes than monolinguals (Gollan \& Acenas, 2004; Gollan \& Silverberg, 2001), and produce longer reaction times than monolinguals on a lexical decision task (Bijeljac Babic, Biardeau \& Grainger, 1997; Ransdell \& Fischler, 1987). These differences are even reported when bilinguals respond in their first and dominant language (Ivanova \& Costa, 2008). All of these tasks depend on vocabulary level and therefore point to a potential challenge for bilinguals in linguistic knowledge and fluent language production. Most studies of bilingual language processing and language proficiency compare bilingual performance in their two languages, determining, for example, the relation between the

\footnotetext{
* This work was partially supported by grant A2559 from the Natural Sciences and Engineering Research Council of Canada and grant MOP57842 from the Canadian Institutes of Health Research to EB. We are grateful to all the past and present members of the Bialystok lab who collected the data and contributed the results to this analysis.
}

dominant and non-dominant languages (e.g., Costa, 2005; Gollan, Salmon, Montoya \& da Pena, 2010). The question for the present study, however, is different: Do bilingual and monolingual adults differ in vocabulary level in the language of the community? This possibility is rarely assessed in the studies reporting differences in levels of linguistic ability noted above.

There are both theoretical and clinical reasons why this issue is important. Theoretically, performance on verbal and, to some extent, cognitive tasks depends crucially on levels of linguistic proficiency. In psycholinguistic studies of linguistic processing and modeling, vocabulary size influences outcomes; for example, word identification depends on the presence and strength of lexical neighbors (e.g., McClelland \& Elman, 1986; Seidenberg \& McClelland, 1989). Moreover, models of language comprehension and production have been based on such tasks as lexical decision, verbal fluency, and picture naming, all of which are sensitive to basic vocabulary knowledge and are performed differently by bilinguals. If bilingual speakers do not have language proficiency equivalent to monolingual speakers, then such models may need to be revised to accommodate proficiency differences associated with bilingualism.

An example of the influence of vocabulary knowledge on linguistic performance comes from the verbal fluency task. The basic procedure is to ask participants to generate as many words as possible in 60 seconds, words that satisfy a criterion determined either by the category (semantic fluency) or the initial letter of the word (phonological fluency). Vocabulary size is positively related to performance in these tasks in both younger and older 
monolingual adults (Hedden, Lautenschlager \& Park, 2005; Salthouse, 1993). However, bilingual participants typically produce fewer words than monolingual participants, even if they are allowed to produce words in both languages (Gollan et al., 2002). In a behavioral study of monolingual and bilingual young adults, performance of the bilinguals depended on their receptive vocabulary scores in English, the language of testing (Bialystok, Craik \& Luk, 2008b). More dramatically, the actual process by which individual words were retrieved was shown in a time-course analysis to be different for bilinguals than monolinguals and different for bilinguals with higher receptive vocabulary than for those with a lower receptive vocabulary (Luo, Luk \& Bialystok, 2010). Thus, language production is affected not only by bilingualism but also by vocabulary level in the language of testing, placing limits on the generalizability of theoretical models of language comprehension and production.

The possibility that there are pervasive differences in vocabulary size of monolingual and bilingual adults also has clinical implications. Tests used in neuropsychological assessments for diagnosis are often based on language production, but the clinical interpretations of performance on these tests are determined by monolingual norms. Thus, standard versions of the verbal fluency such as in the DelisKaplan Executive Function Battery (DKEFS; Delis, Kaplan \& Kramer, 2001) and the Controlled Oral Word Association Test (COWAT; Strauss, Sherman \& Spreen, 2006) are used diagnostically to determine the integrity of brain function and the presence of neurological disease. Clinicians, however, are unlikely to make adjustments in the standardized scores to account for bilingualism or more generally even determine whether or not a patient is bilingual. The real possibility that standard assessment is misleading for bilingual patients creates the potential for misinterpretation at best and misdiagnosis at worst. Since vocabulary is key to these results, it is important to establish whether or not there are systematic differences in vocabulary size for monolingual and bilingual adults.

One standardized method to evaluate vocabulary level is the Peabody Picture Vocabulary Test (PPVT-III). Participants are shown a plate with four pictures and indicate which one corresponds to a word spoken by the experimenter. Items become progressively more difficult and testing stops when an error criterion has been met and raw scores are converted to standard scores based on the participant's age. These standard scores have a population mean of 100 and standard deviation of 15 .

Individual studies that have compared monolingual and bilingual participants for PPVT test scores in English have had mixed results. In some studies monolingual and bilingual participants achieved equivalent scores (e.g., Bialystok, Craik, Klein \& Viswanathan, 2004) but in others, monolinguals outperformed bilinguals in the language of testing (e.g., Portocarrero, Burright \& Donovick, 2007). Thus, the results are inconsistent and it is difficult to extrapolate to the population. The present approach is to combine data from individual studies to estimate the population distribution of a vocabulary score obtained from a large sample of monolingual and bilingual participants. Because the PPVT is a standardized test administered under identical procedures, scores from multiple studies can be combined without regard for the individual study in which the test was administered. Thus, the analysis is a large sample investigation of vocabulary size and is not a meta-analysis of previous studies.

In a recent study, we aggregated the PPVT scores from 1,738 children between three and ten years old (Bialystok, Luk, Peets \& Yang, 2010). As with adults, individual studies produce mixed results for the relation between receptive vocabulary levels for monolingual and bilingual participants, but by examining the data for a large sample of children, estimates come closer to population norms. In the study with children, there was clear evidence that for all ages included, monolingual children obtained significantly higher scores on the receptive vocabulary tests than did bilinguals. More importantly, the scores for both groups were distributed normally, with monolinguals obtaining a mean score of 106.8 and standard deviation of 12.3, and bilinguals, a mean score of 96.3 and standard deviation of 13.0. These results indicate that on average, bilingual children have a smaller vocabulary in the language of testing than do comparable monolinguals.

In the present study, we applied this method to vocabulary data from adults to determine whether such consistent population differences can be found in adulthood.

\section{Method and results}

Data were aggregated from 20 studies conducted by the first author over a period of seven years in which the PPVT-III had been administered to monolingual and bilingual adults. The sample included 1,605 participants between the ages of 17 and 89 years. There were 797 monolingual speakers of English (mean age $=34.8$ years, $\mathrm{SD}=21.1)$ and 808 bilingual participants who spoke English plus another language (mean age $=33.1$ years, $\mathrm{SD}=20.1$ ), with no age difference between groups, $F(1,1603)=2.8, M S E=423.5$, n.s. The non-English language included a large variety of European and Asian languages with no concentration on any one language. All participants lived in an English-speaking multicultural city, reported using both English and their other language on a daily basis, and stated they had high proficiency in both languages. Younger adults had typically been bilingual since at least beginning school and older adults since at least the age of 20 years old (i.e., at least for 50 years). Although English is most often the second 


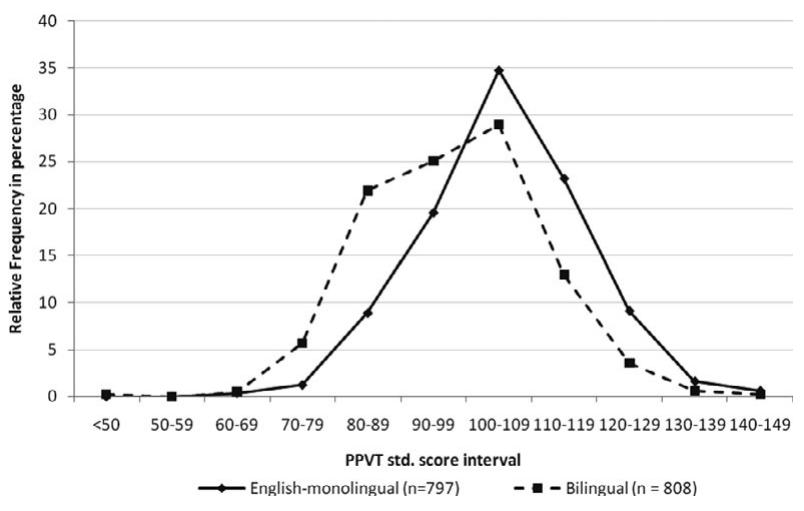

Figure 1 Distribution of PPVT-III standard scores for monolingual and bilingual participants.

language learned (L2), because of the daily use of both languages in an English community English is often the dominant language, making the distinction between L1 and L2 difficult to assess, In the study with children (Bialystok et al., 2010), a comparison of Asian and nonAsian languages indicated no difference in English PPVT scores. Each of the studies from which these participants were extracted included measures to match monolingual and bilingual participants on cognitive variables, but because those measures were different across studies, it is not possible to aggregate cognitive scores for this analysis. However, since the comparability of cognitive level for monolingual and bilingual participants was confirmed individually for each study, it can be assumed that the total sample of monolingual and bilinguals participants is also equivalent on such measures.

The analysis was based on the age-corrected standard scores from the PPVT-III. The relative frequency distributions of standard scores for monolingual and bilingual participants are presented in Figure 1. Univariate statistics indicated that these frequencies were normally distributed, with skewness indices of 0.30 and 0.01 for monolinguals and bilinguals, respectively. A perfectly normal Gaussian distribution would result in a skewness index of zero, so the near-zero values indicate that the distributions approximated normality. Note that ANOVA is robust with respect to small deviations from normality in a large sample such as this, so simple tests of normality cannot be interpreted. A one-way ANOVA showed that the mean vocabulary score for the monolinguals was significantly higher than that for the bilinguals, $F(1$, $1603)=138.4, M S E=164.7, p<.0001$. The statistical significance of the difference was confirmed in the nonoverlapping 95\% confidence intervals for monolinguals (104.4, 106.2) and bilinguals $(96.8,98.6)$.

Because the age range was large, participants were divided into subgroups of younger and older adults to determine whether the pattern was consistent across the lifespan. Table 1 presents PPVT standard scores for the monolingual and bilingual participants by age group. A two-way ANOVA for age group and language group showed that older adults scored higher than young adults, $F(1,1601)=24.7, M S E=162.3, p<.0001$, and monolinguals scored higher than bilinguals, $F(1,1601)=$ $105.8, M S E=162.3, p<.0001$, with no interaction, $F<1$.

\section{Discussion}

An analysis of a sample of over 1,600 participants showed that monolinguals obtained significantly higher receptive vocabulary scores than bilinguals in the language generally used for empirical testing, clinical assessment, and theoretical model building. These results replicate those from a similar study with children up to the age of 10 years (Bialystok et al., 2010). Together, the two studies point to a lifelong shift in receptive vocabulary level in the community language for individuals who continue to function in another language as well. Although there is no reason to believe that bilinguals know fewer words in total than their monolingual peers, the evidence from the two studies indicates a significant difference in vocabulary size for the community language.

Although the distribution of PPVT scores approximates the Gaussian distribution for both monolingual and bilingual participants, the shape of the bilingual curve deviates from normality slightly more than does the monolingual curve. In contrast, both distributions were perfectly normal in the study with children (Bialystok et al., 2010). This difference is likely attributable to the greater heterogeneity of adult bilinguals than is the case

Table 1. Mean standard score for the PPVT-III (and standard deviation) for monolingual and bilingual participants by age group.

\begin{tabular}{llllll}
\hline \hline & \multicolumn{2}{c}{ Young } & & \multicolumn{2}{c}{ Older } \\
\cline { 2 - 3 } & Monolingual & Bilingual & & Monolingual & Bilingual \\
\hline Sample size & 606 & 637 & & 191 & 171 \\
Age & $23.9(8.4)$ & $23.5(8.0)$ & & $69.5(6.6)$ & $68.9(6.3)$ \\
PPVT-III std. & $104.2(11.4)$ & $97.1(12.6)$ & & $108.7(16.0)$ & $100.1(14.0)$ \\
\hline \hline
\end{tabular}


for children. The great majority of the bilingual children in our previous study spoke English at school and in the community and another language at home; the adult bilinguals in the present study had more diverse language histories. For example, the adults became bilingual at different ages and under different circumstances, factors that affect proficiency in the new language. In a study of 157 young adults, early bilinguals obtained higher PPVT scores than late bilinguals, all else being equal (Luk, de Sa \& Bialystok, 2011). Similarly, the study by Portocarrero et al. (2007) reported a negative correlation between age of arrival in the United States and PPVT score. Therefore, unlike the children in the previous study for whom English was largely the dominant language, the adults in the present study have a greater variety of language backgrounds and language dominance patterns. Importantly, however, the distribution of scores demonstrates that neither of these factors overrides the general pattern showing a shift in the mean score by language group.

The results also showed an equivalent effect in both the monolingual and bilingual groups in which the older adults obtained higher vocabulary scores than the younger adults. This pattern is consistent with research showing that vocabulary size increases through late middle age, resulting in larger a vocabulary for older adults (review in Burke \& Shafto, 2008). Thus, in spite of an absolute difference in vocabulary level between monolinguals and bilinguals, the normal processes associated with aging and cognitive change were maintained.

Interpretations of research and outcomes of clinical diagnoses make assumptions about language proficiency in general and vocabulary size in particular that may not apply to bilingual populations. The results of the present study point to the importance of objectively determining the vocabulary level of bilinguals in the language in which testing or assessment is taking place. Although the present results have no direct clinical application, they carry significant implications for theoretical interpretations and clinical decisions.

\section{References}

Bialystok, E., Craik, F. I. M., Klein, R., \& Viswanathan, M. (2004). Bilingualism, aging, and cognitive control: Evidence from the Simon task. Psychology and Aging, 19, 290-303.

Bialystok, E., Craik, F. I. M., \& Luk, G. (2008a). Cognitive control and lexical access in younger and older bilinguals. Journal of Experimental Psychology: Learning, Memory, and Cognition, 34, 859-873.

Bialystok, E., Craik, F. I. M., \& Luk, G. (2008b). Lexical access in bilinguals: Effects of vocabulary size and executive control. Journal of Neurolinguistics, 21, 522-538.

Bialystok, E., Luk, G., Peets, K. F., \& Yang, S. (2010). Receptive vocabulary differences in monolingual and bilingual children. Bilingualism: Language and Cognition, 13, 525-531.

Bijeljac Babic, R., Biardeau, A., \& Grainger, J. (1997). Masked orthographic priming in bilingual word recognition. Memory \& Cognition, 25, 447-457.

Burke, D. M., \& Shafto, M. A. (2008). Language and aging. In F. I. M. Craik \& T. A. Salthouse (eds.), The handbook of aging and cognition (3rd edn.), pp. 373-443. New York: Psychology Press.

Costa, A. (2005). Lexical access in bilingual production. In J. F. Kroll \& A. M. B De Groot (eds.), Handbook of bilingualism: Psycholinguistic approaches, pp. 308-325. New York: Oxford University Press.

Delis, D. C., Kaplan, E., \& Kramer, J. H. (2001). Verbal fluency subtest of the Delis-Kaplan Executive Function System. San Antonio, TX: The Psychological Corporation.

Gollan, T. H., \& Acenas, L. A. (2004). What is a TOT? Cognate and translation effects on tip-of-the-tongue states in Spanish-English and Tagalog-English bilinguals. Journal of Experimental Psychology: Learning, Memory, \& Cognition, 30, 246-269.

Gollan, T. H., Fennema-Notestine, C., Montoya, R. I., \& Jernigan, T. L. (2007). The bilingual effect on Boston Naming Test performance. Journal of the International Neuropsychological Society, 13, 197-208.

Gollan, T. H., Montoya, R. I., Fennema-Notestine, C., Morris, S. K., (2005). Bilingualism affects picture naming but not picture classification. Memory \& Cognition, 33, 12201234.

Gollan, T. H., Montoya, R. I., \& Werner, G. (2002). Semantic and letter fluency in Spanish-English bilinguals. Neuropsychology, 16, 562-576.

Gollan, T. H., Salmon, D. P., Montoya, R. I., \& da Pena, E. (2010). Accessibility of the nondominant language in picture naming: A counterintuitive effect of dementia on bilingual language production. Neuropsychologia, 48, 1356-1366.

Gollan, T. H. \& Silverberg, N. B. (2001). Tip-of-the-tongue states in Hebrew-English bilinguals. Bilingualism: Language and Cognition, 4, 63-83.

Hedden, T., Lautenschlager, G., \& Park, D. (2005). Contributions of processing ability and knowledge to verbal memory tasks across the adult life-span. The Quarterly Journal of Experimental Psychology A, 58, 169-190.

Ivanova, I., \& Costa, A. (2008). Does bilingualism hamper lexical access in speech production. Acta Psychologica, 127, 277-288.

Luk, G., de Sa, E., \& Bialystok, E. (2011). Is there a relation between onset age of bilingualism and enhancement of cognitive control? Bilingualism: Language and Cognition, 14 (4), 596-596.

Luo, L., Luk, G., \& Bialystok, E. (2010). Effect of language proficiency and executive control on verbal fluency performance in bilinguals. Cognition, 114, 29-41.

McClelland, J. L., \& Elman, J. L. (1986). The TRACE model of speech perception. Cognitive Psychology, 18, 1-86.

Portocarrero, J. S., Burright, R. G., \& Donovick, P. J. (2007). Vocabulary and verbal fluency of bilingual and monolingual college students. Archives of Clinical Neuropsychology, 22, 415-422. 
Ransdell, S. E., \& Fischler, I. (1987). Memory in a monolingual mode: When are bilinguals at a disadvantage? Journal of Memory and Language, 26, 392-405.

Roberts, P. M., Garcia, L. J., Desrochers, A., \& Hernandez, D. (2002). English performance of proficient bilingual adults on the Boston Naming Test. Aphasiology, 16, 635-645.

Rosselli, M., Ardila, A., Araujo, K., Weekes, V.A., Caracciolo, V., Padilla, M., \& Ostrosky-Solis, F. (2000). Verbal fluency and repetition skills in healthy older Spanish-English bilinguals. Applied Neuropsychology, 7, 17-24.
Salthouse, T. A. (1993). Speed and knowledge as determinants of adult age differences in verbal tasks. Journal of Gerontology: Psychological Sciences, 48, 29-36.

Seidenberg, M. S., \& McClelland, J. L. (1989). A distributed, developmental model of word recognition and naming. Psychological Review, 96, 523-568

Strauss, E., Sherman, E. M. S., \& Spreen, O. (2006). A compendium of neuropsychological tests: Administration, norms and commentary. New York: Oxford University Press. 